\section{A Comparative Study on Turkey's National Green Building Certification System Under Energy Policy Developments}

\section{Abstract}

In today's living conditions, the quality of life depends on wellmanaged energy. Therefore, countries produce different energy policies to manage their energy resources. Determining appropriate, feasible, and controllable energy policies becomes important especially for buildings, as being one of the most significant energy consumers. Green building certification systems (GBCSs) are one of the most common applications for energy efficiency in the building sector.

\section{Purpose}

This paper is a comparative analysis of GBCSs in developed and developing countries, in an effort to establish the similarities and differences between Turkey's first national GBCS - B.E.S.T and other GBCSs, and to determine how the energy criteria in GBCSs contribute to each dimension of sustainability (i.e., environmental, economic, social).

\section{Design/Methodology/Approach}

The research methodology depends on the literature review and documentary review on energy-related regulations, legislation, and laws. A comparative analysis of GBCSs was conducted in the study. Not only the sub-criteria directly exist under the energy criterion, but also

\section{Filiz Umaroğulları* Semiha Kartal ${ }^{\star *}$ Dinçer Aydın ${ }^{* \star *}$}

Keywords: B.E.S.T, CEDBIK, energy, Green Building Certification System (GBCS), sustainability dimension

${ }^{*}$ Assist. Prof. Dr. in Department of Architecture, Trakya University, Edirne, Turkey.

Email: filizu@trakya.edu.tr ORCID No: https://orcid.org/00000002-9503-1816

${ }^{* *}$ Assoc. Prof. Dr. in Department of Architecture, Trakya University, Edirne, Turkey.

Email: semihak@trakya.edu.tr ORCID No: https://orcid.org/00000001-6274-488X

${ }^{* * *}$ Res. Assist. in Department of Architecture, Trakya University, Edirne, Turkey.

Email: dinceraydin@trakya.edu.tr ORCID No: https://orcid.org/00000001-8436-6330 
indirect energy criteria, which are included in the sub-criteria of all other criteria within the GBCS, were numerically evaluated with the helped of developed matrix.

\section{Findings}

The results show that energy credits were given the highest weight by LEED $(\sim 33 \%)$ in international GBCSs and by GRIHA $(\sim 42 \%)$ in national GBCSs. In B.E.S.T, this is $\sim 29 \%$. It was determined that B.E.S.T was structurally similar to LEED, while it was similar to BREEAM in terms of weight and importance given to the energy criteria. According to the developing country GBCSs, the biggest similarity is seen with GBI. In terms of SD, it is found that GBCSs present similar characteristics to their regional development level. Where a GBCS serves for a developing region, the main concerns of energy criteria focus on the intersection of its environmental and economic aspects. Thus, B.E.S.T has been created in a similar structure and the highest share (\%80) on environmentaleconomic aspects.

\section{Research Limitations}

In the study, the comparison was made between selected international GBCSs like BREEAM, LEED, and DGNB and national GBCSs like GM, GBI, and GRIHA.

\section{Practical Implications}

In practice, the results can help owners or developers to focus on which energy criteria contribute economic, social or environmental advantage for them.

\section{Social Implications}

This study also provides some recommendations for further application and academic studies of B.E.S.T.

\section{Originality/Value}

Increasing the recognition of Turkey's national GBCS in scientific researches and contributing to the development of it have made this study original and unique.

\section{INTRODUCTION}

In recent years, how to reduce energy use has become a topic of high interest, and many studies on the different scales are conducted (Gillingham et al., 2006; Calero et al., 2018; Naylor et al., 2018). With the awareness of energy, all countries, depending on their development levels (DLs), establish different energy policies by considering the environmental, economic and social effects of this issue (Rosenow and Galvin, 2013; Kim and Sun, 2017; Yu et al., 2017). The number of buildings rising parallel to world population growth causes an increase in energy demand. Although rapid urbanization occurs, cities take $2 \%$ space in the world. However, only this is enough to make cities one of the biggest energy consumers, which consumes $80 \%$ of energy and produces $80 \%$ of greenhouse gases (GHG) (Hoornweg et al., 2011). This is not a proper and sustainable approach to expand cities by maintaining the existing situation (Johansson and Goldemberg, 2002). 
In today's cities, only buildings are responsible for $40 \%$ of total energy, $70 \%$ of total electricity consumption and $30 \%$ of GHG emission in which residential buildings are about 38\% (EIA, 2018; Hoornweg et al., 2011). Therefore, developing policies such as reducing energy consumption, controlling the consumption, using and extending alternative and renewable energy resources (RERs) in the building sector become inevitable. Because the critical aspect of achieving to live in cities with a sustainable way depends on energy sustainability (Rosen, 2009). This leads to aiming at sustainable construction in the building sector. Such that green buildings (GBs), which are a process of creating a healthy built environment under the principles of resource efficiency and ecological consideration, are the basic application of sustainable construction (Kibert, 2016).

Recently in sustainable construction, green building certification systems (GBCSs) are one of the most common and popular policies and/or tools for energy efficiency. In the literature, it is seen that after the emergence of GBCSs, studies examining GBCSs with different objectives are carried out intensely. In the last two decades, GBCSs are the second most studied topic after the GB project delivery and developments in the GB literature (Darko and Chan, 2016). While some studies focus on the overall analysis on criteria of GBCS (Lee, 2013; Illankoon et al., 2017; Shan and Hwang, 2018), others on only energy (Roderick et al., 2009), water (Waidyasekara et al., 2013), waste management (Wu et al., 2016) or health and comfort (Worden et al., 2020). With their integrated system, GBCSs aim to decrease the energy use of buildings and to make buildings healthier and more environmentally friendly for their occupants (Sev, 2011; Khoshbakht et al., 2018).

GBCSs are a kind of driver for the sustainability and/or success criterion of a building. Furthermore, sustainability recognizes a balance between the economic, social, and environmental dimensions (Brundtland, 1987). This is also known as "the triple bottom line" (Elkington, 2013) and called as sustainability dimension (SD) in this study. GBCSs include SDs at different levels depending on the weight and context of their criteria. It is seen that so limited studies focus on the SD of the evaluation criteria of GBSCs completely or separately (Awadh, 2017; Doan et al., 2017; Jensen and Birgisdottir, 2018). Therefore, a comparative analysis of GBCSs in terms of their SD becomes a significant issue. This helps to analyze how a GBCS aims to provide sustainability giving to high priority on its surrounding. This can be also considered as an indicator to show the DL of a nation. Because the weight given to the SD varies according to the DL of the countries. Thus, it is also expected a change in the SD of GBCSs. 
Starting with the first GBCS in 1990, this process continues today with the development of dozens of national and international GBCSs. After the success of international GBCSs, global awareness occurred to construct buildings more energy efficient. In time, some of the GBCSs became more popular in building evaluation systems. However, countries' national needs and building sector dynamics cause creating their own GBCS. One of these national GBCSs is B.E.S.T (Ecological and Sustainable Design in Buildings), which is Turkey's first official national GBCS and generated based on the international GBCSs by CEDBIK (Turkish Green Building Council).

In the literature, many studies have emphasized the need for a national GBCS for Turkey (Gültekin and Bulut, 2015; Erdede and Bektaş, 2018a). Following the first draft, although various studies on B.E.S.T, also known as CEDBIK, were carried out, these are mainly macro-scale comparisons of existing GBCSs or their selection processes (Geçimli and Yamaçli, 2019; Sait and Harputlugil, 2019). Moreover, some studies are aimed at comprehensively examining one or more parameters of B.E.S.T that are topics on water efficiency in GB (Gültekin et al., 2018), site usage (Erdede and Bektaş, 2018b), daylight comfort performance (Durak and Ayyldız, 2018), innovation in GBs (Mollaoglu et al., 2016), and its effect on urban transformation (Diker, 2019). However, it is seen that no detailed research has been conducted regarding the energy parameter yet. When considered the importance of energy for Turkey as a country dependent on foreign energy, energy is an important issue that should be examined.

The main objective of this study is to examine the international and national GBCSs in terms of energy criteria. In addition, this study is a comparative analysis of GBCSs in developed and developing countries, in an effort to establish the similarities and differences between B.E.S.T and other GBCSs, and to determine how the direct or indirect energy criteria in GBCSs contribute to each SD depending on DLs of countries. In this scope, the study was conducted as follow: (1) summarization of energy-related regulations until the emergence of GBCSs, (2) identification of the selected GBCSs and their key parameters, (3) comparison of the GBCSs, (4) discussion on the importance of energy criteria by evaluating the key credits awarded for energy efficiency and (5) determination the SDs of energy criteria.

To make a more cohesive comparison, this study has a restriction on the selection of the GBCSs. Due to generation of B.E.S.T depends on three widespread and well known international GBCSs, BREEAM (BRE Environmental Assessment Method), LEED (Leadership in Energy and Environmental Design) and DGNB (German Sustainable Building Council) were chosen as 
international GBSCs. Besides, Turkey is a developing country so that national GBCSs belonging to other developing countries like GM (Green Mark) from Singapore, GBI (Green Building Index) from Malaysia, and GRIHA (Green Rating for Integrated Habitat Assessment) from India were included in this comparative examination.

\section{RESEARCH BACKGROUND}

Nowadays, the management of energy with energy-saving policies is so critical. Therefore, to achieve sustainable development, countries are trying to re-evaluate their energy systems by planning their energy programs and strategies according to their energy efficiency aims and targets (Yüksel and Kaygusuz, 2011). In the 20th century, instead of local and vernacular architectural solutions of the 18th century, using products, equipment and energy-consuming systems developed by the influence of industrialization made buildings have a significant share of energy consumption. The buildings fit with active energy-consuming systems have become the environments threaten user health. However, after energy crises, energy efficiency decisions that were put forward after 1975 in the developed countries have resulted in a saving of $55 \%$ in energies consumed until 2005. Due to high importance on energy efficiency in the 1990s, total energy consumption in the world has not increased and has remained at a lower rate while industrialization and growth are occurring (Yaman et al., 2015). In the $21^{\text {st }}$ century, buildings have been designed by removing systems increasing energy consumption. An approach was adopted in which energy reducing systems are used; physical environmental conditions are well analyzed; passive energy designs are applied (Goldemberg et al., 1987).

To regulate and decrease the energy consumption of buildings, some policies, which can be called as GB policies, are set. In literature, these can be summarized as requiring an energy performance building directive, using and also promoting RERs instead of non-RERs, encouraging to design GBs by regulating with laws, rules, taxes, creating a council or institution to arrange and to control the relevant standards, encouraging to get a GBCS (Pearce et al., 2007; Murphy, 2014; Tan et al., 2016; Huo and Yu, 2017). Figure 1, which is listing developments directly related to the energy consumption of the building sector, summarizes the important milestones of these policies with the help of a chronological chart established by using the data obtained from the literature.

According to Figure 1, despite the increased dependence of oil and natural gas after the 1950s, discoveries of hydrogen, solar, wind, and geothermal energies, have already occurred until that 
time. It is seen that these RERs were used for the first time in the $19^{\text {th }}$ century. However, becoming widespread commercial usage of them took time. In the $20^{\text {th }}$ century, it was possible to use RERs economically in buildings. Furthermore, in the $21^{\text {st }}$ century RERs can have a wide and effective usage area in the building sector.

Figure 1. Comparison chart of directly energy-related regulations in building sector

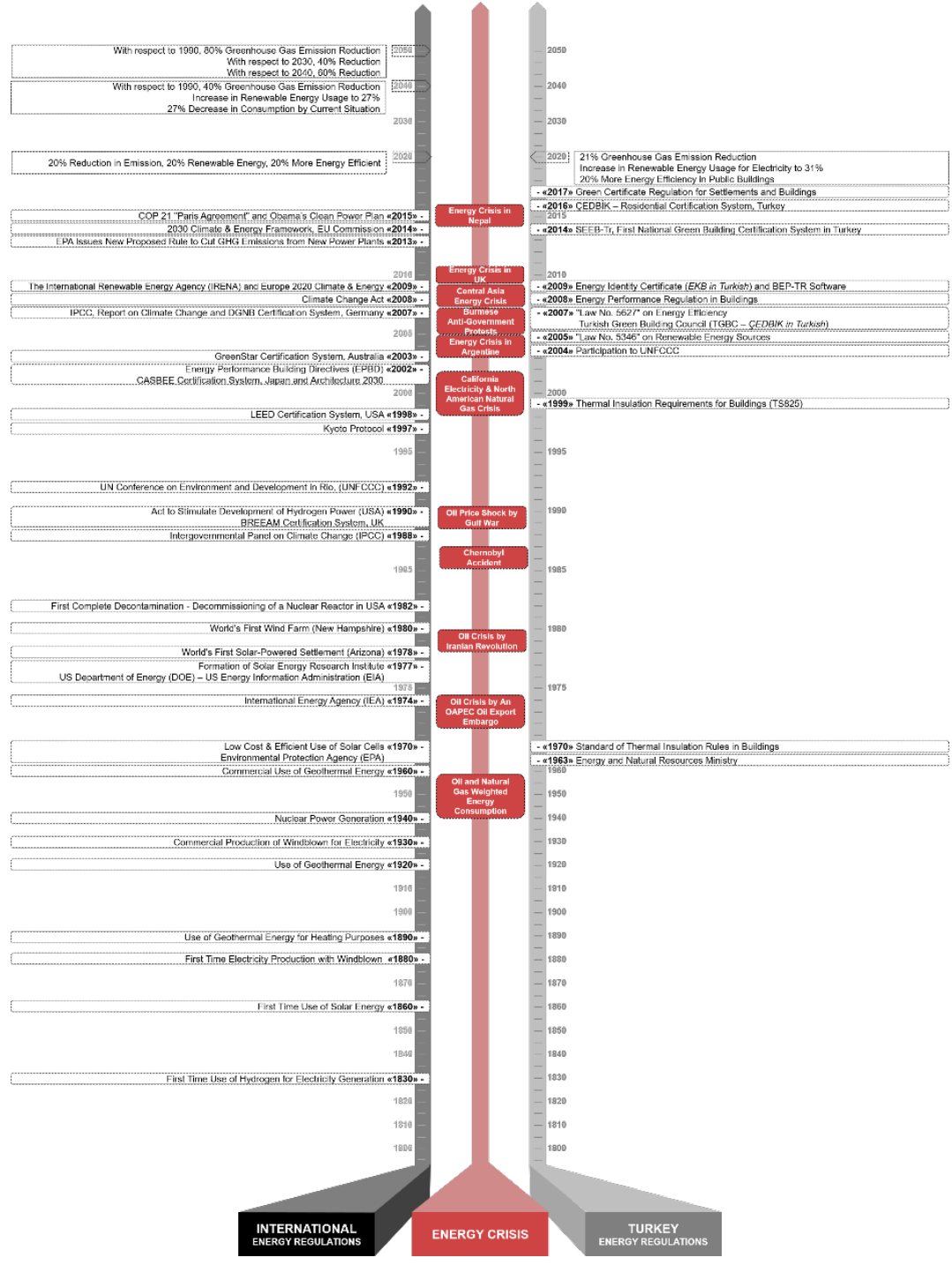

The global energy crises of 1973 and 1979 necessitated the establishment of an energy governance institution to regulate, control, and follow-up energy issues in developed countries. Therefore, IEA (International Energy Agency) was instituted as a global regulator in 1974 (Figure 1). This was followed by the establishment of a Ministry of Energy in the same year in the UK and 1977 in the USA. Energy and Natural Resources Ministry was established in Turkey in 1963, before these countries and the global energy crisis. However, Turkey, whose industrialization process was much slower, did not have an effective mission/role in energy management in that period. 
The establishment of some international institutions or organizations also helps to regulate the energy efficiency of buildings such as IPCC (Intergovernmental Panel on Climate Change) in 1988, UNFCCC (United Nations Framework Convention on Climate Change) in 1992 and then the first COP (Conferences of the Parties) in 1995 (Figure 1). In 1997, the Kyoto Protocol, one of the largest participated agreements on a global basis for sustainability, has led countries to reshape their energy policies (Oberthür and Ott, 1999).

After Kyoto Protocol, the most important step taken by EU countries for the building sector is to generate and to apply the "Energy Performance Building Directive (EPBD)" in 2002 (Nikolaou et al., 2015). While EPBD allows decreasing the energy consumption of the $75 \%$ building stock in the EU, this also helps achieve energy efficiency targets of EU countries by reducing the EU's total energy consumption by $5-6 \%$ and lowering $\mathrm{CO}_{2}$ emissions by about $5 \%$ (EC, 2018). In Turkey, one of the major legal regulations to reduce the energy consumption of the building sector is "Thermal Insulation Requirements for Buildings (TS825)". However, the fact that the TS825 is not mandatory restrains obtaining energy saving. Although it has become a compulsory regulation for all newly constructed buildings after revision in 2008, its contribution to efficiency is so limited.

It was decided by the EU to apply the "20/20/20 Climate \& Energy Package" in 2009 to reach the energy targets projected in the Kyoto Protocol. Accordingly, EU countries have agreed to be $20 \%$ more energy-efficient, use $20 \%$ more RERs, produce $20 \%$ less GHG in 2020 than in 1990. Turkey's 2020 energy targets include a $21 \%$ reduction in GHG, a 31\% increase in the use of RERs for electricity, and 20\% more energy efficiency in public buildings. Both Turkey and other countries have been gradually increased their targets for 2040 and 2050.

GBCSs serve as an aid in achieving the energy targets of countries, prioritizing energy efficiency, and encouraging the use of RERs (Figure 1). GBCSs emerged in the 1990s for the first time have encouraged the creation of many national certification systems because of the understanding of their contribution to sustainability and energy efficiency (Li et al., 2017; Mattoni et al., 2018). This made GBCSs become an important tool to achieve the energy efficiency targets of many countries. After the emergence of BREEAM in 1990, many GBCSs were created as LEED in the USA in 1998, CASBEE in Japan in 2002, GreenStar in Australia in 2003, DGNB in Germany in 2007. These GBCSs primarily were generated to meet their own national needs of the building sector. However, their full content made some GBCSs turn into international certification systems or guided to establish 
countries' national certification. Especially, some countries needed to create their national GBCS to decrease energy consumption.

Turkey, which is one of the countries showing the most rapid increase in energy consumption in the world by importing $70 \%$ of its energy, is trying to develop a national GBCS. Until the 2010s, Turkey used only international GBCSs. However, to answer the Turkish construction industry and its culture, Turkey started to develop its national GBCS for the first time in 2008 with the help of Mimar Sinan Fine Art University. In 2013 SEEBTR (Sustainable Energy Efficient Buildings) was generated as a national GBCS in Turkey. Then, the CEBDIK certification system was established in 2013. With CEDBIK, it is aimed to contribute to the economy of the country by providing the formation of healthy societies in a comfortable environment. This certificate will be legally enforced under the Green Certificate Regulation for Settlements and Buildings issued by the Ministry of Environment and Urbanization in 2017. With the last update in 2019, this GBCS is called "B.E.S.T".

According to literature, a LEED-certified building uses 25\% less energy compared to a non-certified one with the same characteristics, and a reduction of $13 \%$ in energy consumptionrelated emissions and a 15\% reduction in energy costs (DLA Piper, 2014; LEED, 2020). The efficiencies provided in energy are very important for countries like Turkey, due to importing a large part of its energy. Therefore, the use of B.E.S.T will also provide a valuable contribution to Turkey's energy targets. In a developing nation, GM developed by Singapore in 2008 has been able to reduce energy consumption by $9 \%-13 \%$ over in the seven years up to 2015 (BCA, 2017). This clearly shows that GBCSs have a significant impact on energy efficiency not only in developed regions but also in developing ones. Thus, this can prove that like a developing country, Singapore, a GBCS in Turkey, will help to increase its energy efficiency.

\section{Brief Introduction to GBCSs}

GBCSs, which are one of the energy-saving applications for buildings, were developed over the past three decades by countries depending on their energy policies (Awadh, 2017; Doan et al., 2017). With GBCSs, it is aimed at a reduction in energy consumption of buildings and their environmental impacts during construction, and sustainable management and operation (Kubba, 2010; Mattoni et al., 2018). However, GBCSs base on volunteerism. In general, GBCS is an assessment method analyses energy consumption, land use, indoor environmental quality, and its impact on human health. 
Many GBCSs have been developed based on the different characteristics, energy and environment targets, and requirements of each country (Kubba, 2010; Kubba, 2012). This causes some differences at the SD of GBCSs depending on the sustainability policy of nations. However, it is important that while developing policies like GBCSs, sustainability pillars must be considered (Sev, 2009).

The first GBCS developed in the world is BREEAM, which was generated by the UK in 1990 (BREEAM, 2020). BREEAM then was used as a guide for other countries' GBCSs. One of the GBCSs influenced by BREEAM is LEED, which was developed by the USA in 1998 and has become the most popular GBCS in the world (Scheuer et al., 2002; Reed et al., 2010). Figure 2 shows both international and national GBCSs. The fact that GBCSs, usually organized as national certification systems, can be adapted to the needs of other countries makes it possible to use them as a global certification (Mattoni et al., 2018). It seems that international certifications are generally used by countries that have a common social, cultural, and economic condition by revising the certification according to their national needs. Use of LEED in Mexico as LEED Mexico and in Brazil as LEED Brazil, and use of BREEAM in the Netherlands as BREEAM Netherlands and in Norway as BREEAM-NOR are examples of the adaptation of GBCSs (Figure 2).

The national GBCS in Turkey to contribute to its energy efficiency policies was generated later than the many countries. The first study taken in this context started with the formation of SEEB-TR in 2008, but SEEB-TR certified building does not exist in Turkey. Therefore, SEEB-TR can be considered as a kind of theoretical application of GBCS. CEDBIK as being a nongovernmental organization on sustainability formed a GBCS. The National Energy Efficiency Action Plan of Turkey prepared by the Ministry of Energy in 2016 and the law of Green Certificate Regulation for Settlements and Buildings in 2017 provided the legal basis for the creation of this certification. Thus, CEDBIK has developed the officially national GBCS - B.E.S.T - with the help of cooperation with the academia, public, and member companies by examining the widespread international GBCSs as BREEAM, LEED and DGNB. In this process, Turkey's national condition, culture, geography, and climate were taken into account by considering the international and EU standards (CEDBIK, 2020). However, the first evaluation system was prepared only for the new construction of residential buildings. 


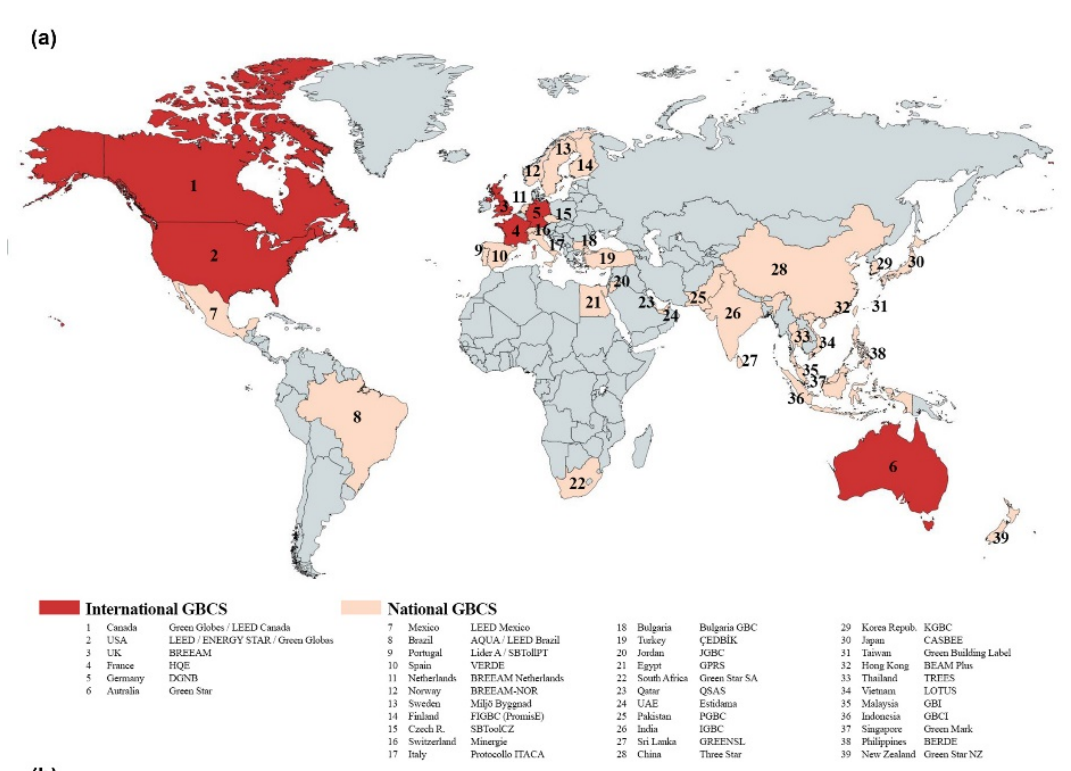

Figure 2. (a) Distribution of various GBCSs used around the world, (b) distribution of BREEAM, LEED and DGNB certified buildings in the world (b)

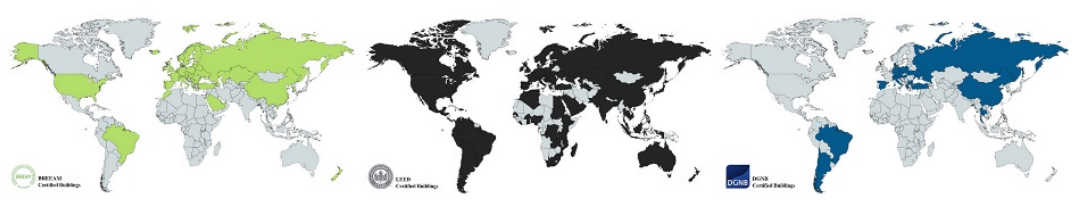

Despite the delay in the emergence of a national GBCS in Turkey, there are totally of 430 certified projects including 388 LEED, 40 BREEAM, 1 DGNB, and 1 Green Globes (CEDBIK, 2020; DGNB, 2020; Green Globe, 2020). Turkey, with the total area of its LEED-certified projects, is located on sixth rank in the world (LEED, 2020). According to the distribution of BREEAM, LEED, and DGNB certified buildings worldwide in Figure 2, although BREEAM is the first GBCS, globally, the most common GBCS is LEED. It is also seen that BREEAM is generally preferred in developed countries, particularly in Europe, and DGNB is used in similar geography but the more limited area (Figure 2). However, a LEED-certified building is found in almost all countries except for some parts of Africa. This shows that LEED's global awareness is the largest, and its content is globally more appropriate or adaptable.

\section{METHODOLOGY}

This study comparatively discusses the energy credit weighting given by the selected GBCSs because energy is the most important parameter in GBCSs (Illankoon et al., 2017; Shan and Hwang, 2018). Each GBCS must meet with SDs, but it changes from one GBCS to another. Especially considering the energy criterion, it is seen that it shows different SD distribution. Therefore, the GBCSs are also analysed with respect to their energy criteria, addressing and prioritizing the sustainability pillars. 
In the study, the data compiled through literature review sourced from papers, proceedings, reports, and information available on the websites of GBCSs. In addition, a numerical analysis has been conducted as a method to calculate and to categorize each GBCS credits under SD. The examined GBCSs in the study are not random selections. This was conducted in two ways one for selection of the international GBCSs and the other for the national. International GBCS were selected from the GBCS used as a guide for the creation of B.E.S.T. These are BREEAM, LEED, and DGNB, which are also widespread GBCSs in the world. In the selection of the national GBCSs, the main concern is to belong to a developing country. Although there are many national GBCSs in the developing nations, another limitation is to have similar sustainable construction activities. According to the top 10 regions for LEED green building, India is the third country where Turkey is sixth (LEED, 2020). Singapore and Malaysia, as being developing countries, are in the top ten countries about economic indicators on sustainable construction (de A. Dias et al., 2017).

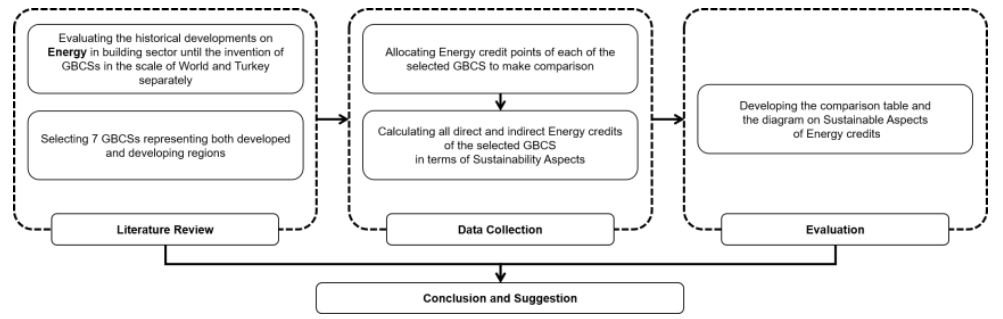

The research methodology is summarized in Figure 3. Firstly, a literature review was conducted in the study. The development of GBCSs was handled along with other developments in the building sector within the historical perspective. According to data, a comprehensive comparison chart was created (Table 1). By considering the research focus, energy credits of each of the selected GBCS were allocated. Then, a comparison matrix was developed, including all direct and indirect energy criteria of the GBCSs by making the calculation for each SD by taking the point value of the criterion into account in the same weight. These credits were converted to share values over 100 (Table 2).

The second step was to allocate credits of energy criteria to the relevant SD. For example, 'use of RERs' is one of the energy subcriteria in LEED. This is attributed to 'environmental-economic' aspect with its proper credits. Likewise, all energy credits of each GBCS were attributed to the relevant SD. After attributing all credits to the relevant SD, the share of SD of all energy-related criteria was determined. According to data, a comparison diagram was developed to analyse the GBCSs (Figure 4).
Figure 3. Research methodology 
Finally, the study was concluded by evaluating both the overall SD of each GBCS in the literature and their SD specific to energy criteria. At this step, an evaluation has been made by taking into consideration the DL of the countries and the importance of energy for them.

\section{COMPARATIVE ANALYSIS of GBCSS}

According to Table 1, current versions of all GBCSs are updated soon. This means that they adapt themselves to changing conditions. This is important to make GBCSs a sustainable tool. Apart from GM, national GBCSs are used for only their regions. GBCSs gain international status when they adapt themselves to local conditions. However, BREEAM and LEED have a significant difference in terms of flexibility and the number of certified buildings. 572,661 buildings were certified by BREEAM, which is six times higher than those for LEED. BREEAM is used in 87 countries, while LEED is in 167 countries (BREEAM, 2020; LEED, 2020). The most fundamental reason for this difference is that the target mass of BREEAM is European countries. Although LEED has spread to more countries, BREEAM has enabled many more buildings to be certified in a limited geography. This is a result of higher European awareness of sustainability (Doan et al., 2017).

The use of international norms is also very effective to make certification a global certificate. BREEAM and DGNB benefit from EU standards and laws, and LEED from ASHRAE and ISO standards. Being regulated with ISO helps GM to use it in other countries. However, GRIHA and GBI are regulated depending on their national norms while B.E.S.T is based on the relevant legislation issued by the Ministry of Environment and Urbanization in Turkey due to being a national GBCS. This limits B.E.S.T to national use for now.

All GBCS have different evaluation criteria changing depending on the type of project - existing, new construction, and interior as well as settlements. Only B.E.S.T is just to be used for new construction projects with residential function. GBCSs are important tools to certify the sustainability of buildings or settlements. GBCSs can help to obtain energy efficiency targets and policies of a city or a country (Beauregard et al., 2014). Besides sustainability, having a certificate also provides project/building recognition and reputation (Shan and Hwang, 2018). 
Table 1. Comparison of green building certification systems

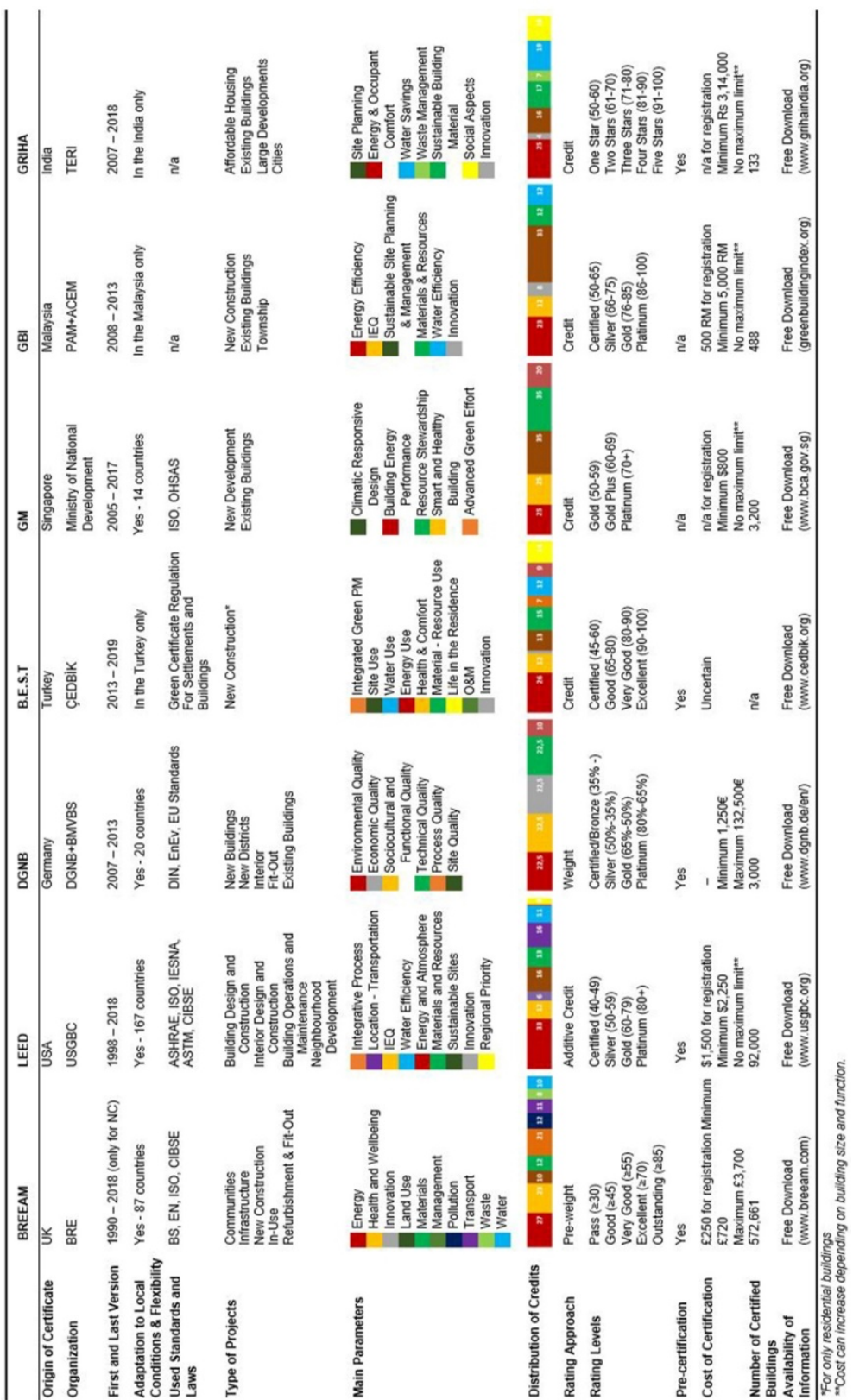

Moreover, GBCSs cause additional cost to the construction budgets. This cost consists of three different items as registration to the GBCS, evaluation of the building, and certificate cost (Table 1). The registration fee and the certificate fee are the common costs for all. However, there are two different methods to calculate the evaluation fee, depending on the size of the project. In BREEAM and DGNB evaluation fee is calculated according to the determined project size limits. In others, this is made considering the unit price per square meter of each project. Therefore, no maximum certification value exists, and LEED has the highest cost. The negative impact of GBCSs on the project cost can be transformed into an economic advantage. A certified building has an average of $18 \%$ more reputation than the others, 
which in turn leads to a $38 \%$ increase in its value and an $11 \%$ decrease in the operation cost (DLA Piper, 2014). Since B.E.S.T has not been used yet, its fees are not determined. However, it is considered to be cheaper than others as being a national GBCS. In Turkey, there are 813 projects have applied to LEED certification despite its high cost. With B.E.S.T, it can also be said that the number of certified buildings would increase (CEDBIK, 2020).

There are two different rating methods for the evaluation process. BREEAM and DGNB use a method of weighing their scores according to each building type, while others use a credit method based on the overall sum of scores. The differences in methods have a great effect on the final score (Suzer, 2015). B.E.S.T shows similarities with LEED about the rating method. Furthermore, the general structure of B.E.S.T is much more familiar with LEED. Because the building industry in Turkey is mainly used to LEED-certified projects. The result is certified in five different rating levels at BREEAM and GRIHA, but at the others in four. In the DGNB only, it is necessary to have a score of at least limit value for each category and total evaluation to get a certification.

\section{Analysis on Energy Criteria}

GBCSs include many environmental, economic and social parameters. Although some differences exist in the parameters, evaluation criteria generally concentrate five basic parameters as site (location and transport), resources (energy, water, material), indoor environment, socio-economic and management. The main reason makes differences between GBCSs is that each country is launching parameters for its market needs (Waidyasekara et al., 2013). As seen in Table 1, the most important criteria for all certifications except GM and GBI is 'energy'.

As the study was aimed to compare the energy criteria of GBCSs, energy related sub-criteria were also evaluated. It is important that some credits related to energy criteria are covered through different headings in some of the GBCSs. For example, in GM 'energy monitoring' credits are addressed under the 'Smart and Healthy Buildings' criteria. Therefore, to analyse the GBCSs cohesively, all criteria were evaluated, and the matrix in Table 2 was formed. Accordingly, many GBCSs allocated a range of 23-29 points for energy. The maximum credits allocated in the GRIHA, which is 42 points out of 104 (40.3\%). Although, altogether fourteen requirements identified about energy, it is seen that some of them only addressed in each GBCS. GRIHA and B.E.S.T are only GBCSs addressed more than seven requirements relevant to energy. 
Table 2. Matrix for credits distribution on energy criteria at the selected GBCSs

\begin{tabular}{|c|c|c|c|c|c|c|c|c|}
\hline & & & $\begin{array}{l}\text { rnatio } \\
\text { GBCSs }\end{array}$ & & & & nal & \\
\hline & $\begin{array}{l}\text { Energy requirements and } \\
\text { credits distributions in GBCSs* }\end{array}$ & 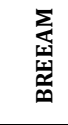 & 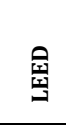 & 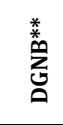 & $\sum_{S}$ & 운 & 这 & فํ. \\
\hline$E_{1}$ & $\begin{array}{l}\text { Reduce building energy use and } \\
\text { increase energy efficiency }\end{array}$ & 15 & 18 & 5 & 12 & 13 & 12 & 15 \\
\hline $\mathrm{E}_{2}$ & $\begin{array}{l}\text { Use of renewable energy and } \\
\text { green power }\end{array}$ & & 5 & & 8 & 5 & 5 & 7 \\
\hline $\mathrm{E}_{3}$ & $\begin{array}{l}\text { Energy evaluation, monitoring } \\
\text { and commissioning }\end{array}$ & 2 & 7 & 7 & 2 & 1 & & 2 \\
\hline $\mathrm{E}_{4}$ & $\begin{array}{l}\text { Energy efficient equipment/ } \\
\text { technology/appliances }\end{array}$ & 2 & & & & & 4 & 1 \\
\hline $\mathrm{E}_{5}$ & Energy efficient transport & 3 & & & & & & 2 \\
\hline $\mathrm{E}_{6}$ & External lightening & 1 & & & & 2 & & 1 \\
\hline$E_{7}$ & $\begin{array}{l}\text { Optimize building design to } \\
\text { reduce conventional energy } \\
\text { demand }\end{array}$ & & & & 5 & & 6 & \\
\hline $\mathrm{E}_{8}$ & Building envelope quality & & & 2 & & & & \\
\hline E9 & $\begin{array}{l}\text { Renewable energy based hot } \\
\text { water systems }\end{array}$ & & & & & & 3 & \\
\hline $\mathrm{E}_{10}$ & $\begin{array}{l}\text { Sustainable maintenance or } \\
\text { operations \& building user } \\
\text { manual }\end{array}$ & & & & & 2 & 2 & 1 \\
\hline $\mathrm{E}_{11}$ & $\begin{array}{l}\text { Low-energy material in interiors } \\
\text { and embodied energy }\end{array}$ & & & & 2 & & 4 & \\
\hline $\mathrm{E}_{12}$ & $\begin{array}{l}\text { Utilization of fly ash in building } \\
\text { structure }\end{array}$ & & & & & & 6 & \\
\hline $\mathrm{E}_{13}$ & Demand response & & 2 & & & & & \\
\hline $\mathrm{E}_{14}$ & $\begin{array}{l}\text { Enhanced refrigerant } \\
\text { management }\end{array}$ & & 1 & & & & & \\
\hline & $\begin{array}{r}\text { Total Points Allocated For } \\
\text { "Energy" Section }\end{array}$ & 27 & 33 & 14 & 29 & 23 & 42 & 29 \\
\hline & $\begin{array}{l}\text { Total Points Including } \\
\text { Innovation and Bonus }\end{array}$ & 132 & 110 & 100 & 140 & 100 & 104 & 110 \\
\hline & (\%) From Total & 20.4 & 30.0 & 14.0 & 20.7 & 23.0 & 40.3 & 26.3 \\
\hline
\end{tabular}

Since it includes regulations for direct energy consumption, except for DGNB, 'reducing building energy use and increasing energy efficiency' has the highest share. The ratio of this criterion among the energy criteria changes between $28.5 \%$ and $56.5 \%$ where the highest share belongs to GBI while the lowest one is DGNB. While international GBCSs pay more attention to energy monitoring after efficient energy use, this trend is towards the use of RERs in developing countries. Because developing countries are aiming to reduce their dependence on energy and gain an economic advantage that will accelerate their development. However, it must be noted that the operation phase of a building is the longest period in its life-cycle. Therefore, energy monitoring is a significant criterion to manage energy consumption. Since developing countries generally focus on short-term gains rather than long-term benefits, the importance they place on this criterion is relatively low.

Energy-saving with passive systems depends on the design of the building envelope and the materials used on it, so DGNB, GM, and GRIHA are the GBCSs giving the credits for the building and 
envelope design. Accordingly, B.E.S.T has the highest similarity with BREEAM and GBI. While LEED is structurally a guide to B.E.S.T, BREEAM is taken as an example for the weight of the criteria. For the sub-criteria, which show some differences under the energy criteria, it can be interpreted that the impact of the habits of the users in the geography causes this.

\section{Sustainability Dimensions of Energy Criteria}

The most important idea behind GBCS includes providing sustainability. Each GBCS presents SD on a different scale. Figure 4 shows the share of the overall SD of BREEAM, LEED, and DGNB. Depending on the DL of countries, the importance given to the environmental, economic, and social aspects of sustainability has changed. Accordingly, the environmental aspect takes the highest share in BREEAM and LEED. They are almost free of economic concerns. However, DGNB gives the highest importance to its social aspect while it is presenting an almost equal balance between the three sustainability pillars. The reason behind this is DGNB was developed later than most of the other certifications and follows the European standards (Jensen and Birgisdottir, 2018).

(a)

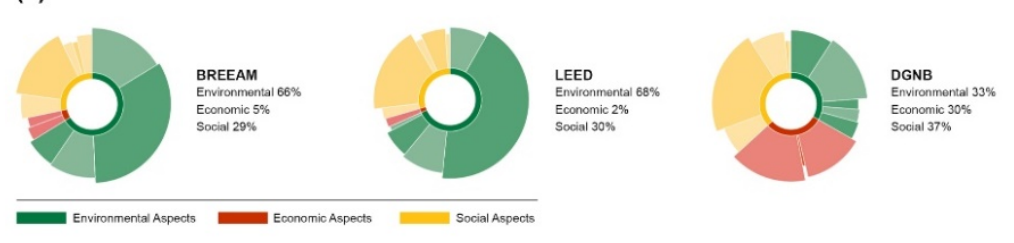

(b)

Figure 4. (a) Overall sustainability dimension of GBCSs: BREEAM, LEED and DGNB, (b) Comparison of the sustainability aspects of energy credits of the selected GBCSs

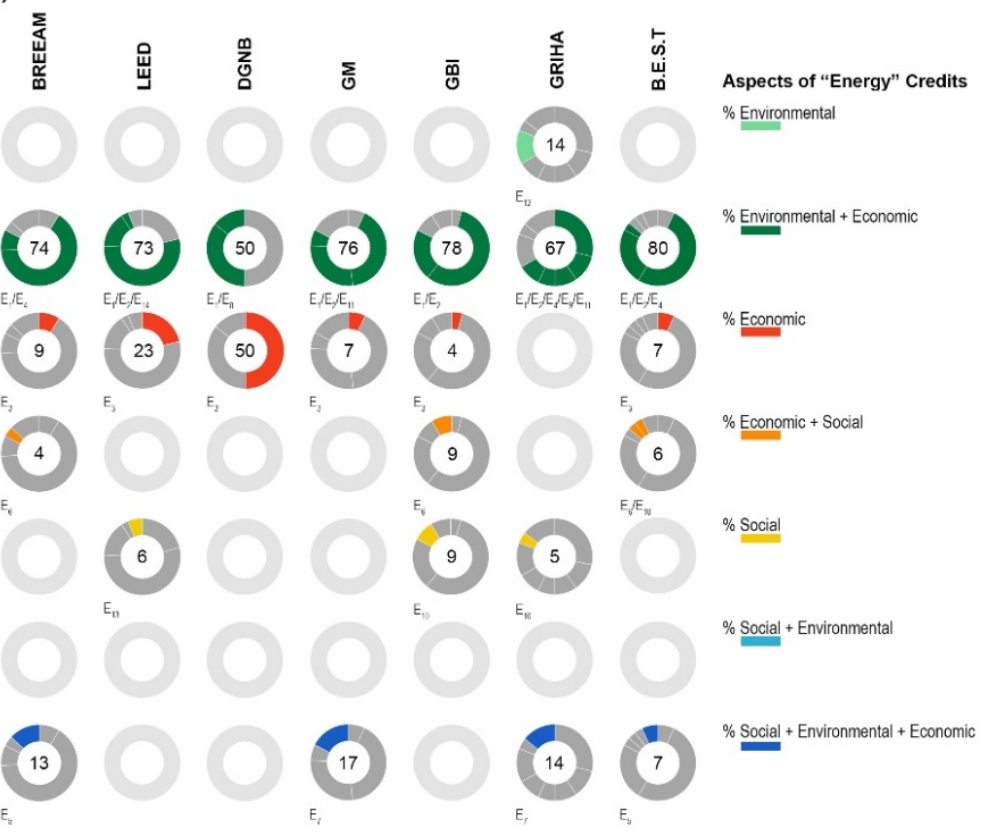


In this study, the analysis categorizes direct and indirect energy criteria from the GBCSs within three SD - environmental, economic, and social aspects. In this framework, the energy credits in each GBCS listed in Table II are examined (Figure 4). In the analysis, the environmental aspect covers the impacts of energy on the natural environment. This aspect also leans toward optimization of resources through reuse and recycling, as well as lowering of environmental impact throughout the building life cycle. The economic aspect deals with the costsaving opportunities of the designs, materials, and applications. The social aspect addresses the human well-being, social interaction, and commitment of users. However, the environmental and social aspects can potentially have an impact on the economic value of the building, and thus, the economic aspect could be argued to become a focus through the other aspects indirectly. For instance, evaluating the 'use of RERs' only environmentally without considering its economic aspect, is not accurate. Therefore, the intersection points of each SD of energy are also considered at forming this diagram (Figure 4).

According to Figure 4, out of DGNB, the intersection of environmental and economic aspects is most heavily weighted in the six GBCSs, followed by the economic aspect in LEED, DGNB and B.E.S.T. While the environmental and economic aspects are almost close to equally weighted, there is a noticeable lack of consideration towards its social and environmental sustainability. Merely one out of the seven selected certifications does not focus on only the economic aspect. DGNB has the highest economic value in terms of energy as well as its overall weighting.

The growth of developing countries is directly related to the economic empowerment of countries (Eggoh et al., 2011; Lemma et al., 2016). For these countries, energy is a key factor has a great economic impact on development. Moreover, the society in which GBCSs serve causes differentiation in the SD of GBCSs. Therefore, the importance of the economy in developing countries necessitates more emphasis on the economic value of the energy criteria in the GBCSs developed by them. The economic aspect with its environmental value has the biggest share in developing countries. However, the most important motivations for GBCS following the environmental aspect of sustainability in developed countries are addressed the social aspect, such as demonstrating social awareness (Figure 4). In developing countries such as India, it is stated that the cost and benefits of the practices, which are mostly directed towards the economic aspect, are given more importance (Potbhare et al., 2009). This argument is a result of the overall evaluation of GRIHA. However, it is found that GRIHA surprisingly does not put 
in the center the only economic aspects of energy. The lack of any energy evaluation, monitoring, and commissioning can be read as one of the reasons for this. For Turkey, B.E.S.T has the highest share on environmental and economic aspects of the energy criteria. Although Turkey is a developing country, the social aspect of energy has not been ignored. Furthermore, the SD of the energy of B.E.S.T shows almost the same characteristic as BREEAM. Accordingly, it can be said that BREEAM has been more effective in determining B.E.S.T's energy criteria than other international certificates.

\section{CONCLUSION}

This study comparatively discusses the similarities and differences between national and international GBCSs. The study is also limited to the examination of the energy criterion of GBCSs because the most important parameter in all GBCS is 'energy'. Therefore, the study presents how and in what approaches energy is addressed in GBCSs of developed and developing countries by examining the SD of direct and indirect energy criteria of GBCSs. The focus of the study has been formed by Turkey's officially first GBCS - B.E.S.T.

The comparison results can be summarized under two groups as energy criteria and SD of energy in GBCSs. The results show that the GBCSs are not homogeneous in terms of energy credits. Energy credits were given the highest weight by LEED $(\sim 33 \%)$ in international GBCSs and by GRIHA $(\sim 42 \%)$ in national GBCSs. In B.E.S.T, this weight is $\sim 29 \%$. Furthermore, apart from developed countries, the use of RERs is the second most significant energy criteria due to its direct effect on reducing the current energy needs of each building in Turkey as well as other developing countries. It is also determined that in B.E.S.T, short-term consumption-reducing practices are given more weight to see direct benefit such as in any other developing countries' GBCSs. However, energy is a multidirectional term, including the sustainability pillars. Environmental, economic, and social aspects of energy criteria change in the GBCSs depending on their DL. It is found that GBCSs present similar characteristics to their regional DL in terms of SD. Where a GBCS serves for a developing region, the main concerns of energy criteria focus on the intersection of its environmental and economic aspects. Thus, B.E.S.T has been created in a similar structure and the highest share $(\% 80)$ on environmental-economic aspects.

To sum up, it is determined that B.E.S.T is structurally similar to LEED, while it is similar to BREEAM in terms of weight and importance given to the criteria. This is an acceptable result, as the Turkish construction industry is more accustomed to LEED practices. In addition, although B.E.S.T places more importance 
to the number of criteria, the biggest similarity in terms of national GBCS is with GBI. It can be said that the relations between these two countries and similar backgrounds are effective on this similarity.

B.E.S.T will positively contribute to the energy efficiency of Turkey soon. However, to achieve this, it is very important to increase the recognition of B.E.S.T. The most basic way to achieve this depends on adding the B.E.S.T to courses that address sustainability issues. In the construction sector, the fact that small and medium-sized construction companies do not see GB construction as a challenge depends on this process to be easily understandable and traceable. This depends on the development of the local GBCS in a national language. These and similar studies have an important role in ensuring the recognition of the certificate developed. The results will also help owners and developers to understand the dimensional contributions of the design, material, and application decisions they will organize for energy in GB constructions. For example, an owner or developer who aims to gain economic benefits can learn what criteria to focus on. Thus, the development of a national GBCS provides advantages to less cost, less time, and more promotion while contributing to an increase in the number of energy-efficient buildings in Turkey.

Moreover, future studies can address the challenges and positive aspects of the B.E.S.T-certified buildings on the construction and operation phase. Also, the numerical results obtained from the applications will make the B.E.S.T more widespread.

\section{REFERENCES}

Awadh, O. (2017). "Sustainability and green building rating systems: LEED, BREEAM, GSAS and Estidama critical analysis", Journal of Building Engineering, 11: 25-29.

BCA (2017). 'Tomorrow Is In Our Hands Annual Report', in Building and Construction Authority, Singapore.

Beauregard, S., Hoque, S., Fisette, P. and Weil, B. (2014). "Is Boston building better? An analysis of the LEED certifiable standard in the Boston zoning code", Journal of Green Building, 9(3): 131-150.

BREEAM (2020). https://www.breeam.com/ (Last Access: May $5,2020)$.

Brundtland, G.H. (1987). 'Our Common Future', in Report of the World Commission on Environment and Development.

Calero, M., Alameda-Hernandez, E., Fernández-Serrano, M., Ronda, A. and Martín-Lara, M.A. (2018). "Energy consumption reduction proposals for thermal systems in residential buildings", Energy and Buildings, 175(15): 121-130. 
CEDBIK (2020). https://www.cedbik.org/ (Last Access: May 8, 2020).

Darko, A. and Chan, A.P. (2016). "Critical analysis of green building research trend in construction journals", Habitat International, 57: 53-63.

De A, Dias, J., Salgado, E.G., Barbosa, S., Alvarenga, A.D. and Lira, J.M.S. (2017). "Assessment of the Sustainability of Countries at Worldwide", Journal of Management and Sustainability, 7(4): 51-64.

DGNB (2020). http://www.dgnb.de/en/(Last Access: May 5, 2020).

Diker, B. (2019). "Kentsel dönüşümde çevresel sürdürülebilirlik üzerine bir araştırma: Fikirtepe örneği", idealkent, 27(10): 594-629.

DLA Piper (2014). 'Towards A Greener Future: Market Report on Sustainable Realestate', in DLA Piper Report, UK.

Doan, D.T., Ghaffarianhoseini, A., Naismith, N., Zhang, T., Ghaffarianhoseini, A. and Tookey, J. (2017). "A critical comparison of green building rating systems", Building and Environment, 123: 243-260.

Durak, Ş. and Ayyıldız, S. (2018). "ÇEDBİK konut sertifikası kapsamında konutların gün ışığından yararlanma performanslarının konfor ve sağlık açısından değerlendirilmesi: İstanbul Pendik örneği", Uluslararası Marmara Fen ve Sosyal Bilimler Kongresi, 23-25 November, pp. 1351-1362, Kocaeli, Turkey.

EC (2018). https://ec.europa.eu/energy/topics/energyefficiency/energy-efficient-buildings/energyperformance-buildings-directive_en (Last Access: August 25, 2019).

Eggoh, J.C., Bangake, C. and Rault, C. (2011). "Energy consumption and economic growth revisited in African countries", Energy Policy, 39: 7408-7421.

EIA (2018). https://www.eia.gov/energyexplained/

Elkington, J. (2013). 'Enter the Triple Bottom Line'. In: The Triple Bottom Line: Does It All Add Up, Ed: Adrian Henriques, Julie Richardson, Routledge.

Erdede, S.B. and Bektaş, S. (2018a). "Türkiye için yeşil bina sertifika sistemi gerekliliği", $2^{\text {nd }}$ International Symposium on Innovative Approaches in Scientific Studies, November 30 - December 2, pp. 138-143, Samsun, Turkey.

Erdede, S.B. and Bektaş, S. (2018b). "Ulusal bir yeşil bina sertifika sistemi için arazi yönetimi kriter önerisi", $2^{\text {nd }}$ International Symposium on Innovative Approaches in Scientific Studies, November 30 - December 2, pp. 182187, Samsun, Turkey. 
Geçimli, M. and Yamaçlı, R. (2019). 'Sürdürülebilir Tasarım Bağlamında Değerlendirme Sistemleri: ÇEDBİK Örneği', Sürdürülebilir Kalkınma Rolüyle Mimarlık, Ed: Leyla Tokman and Ruşen Yamaçlı, Eskişehir Teknik Üniversitesi.

Gillingham, K., Newell, R. and Palmer, K. (2006). "Energy efficiency policies: A retrospective examination", Annual Review of Environment and Resources, 31: 161-192.

Goldemberg, J., Johansson, T.B., Reddy, A.K.N. and Williams, R.H. (1987). 'Energy for A Sustainable World', in World Resources Institute, Washington, USA.

Green Globe (2020). https://greenglobe.com/ (Last Access: May $5,2020)$

Gültekin, A.B. and Bulut, B. (2015). "Yeşil bina sertifika sistemleri: Türkiye için bir sistem önerisi", $2^{\text {nd }}$ International Sustainable Building Symposium, 20-30 May, pp. 813-823, Ankara, Turkey.

Gültekin, A.B., Kaplan, G., Demircan, R.K. and Aruntaş, H.Y. (2018). "Yeşil binalarda su korunumu ölçütlerinin incelenmesi", $3^{\text {rd }}$ International Energy \& Engineering Congress, 18-19 October, pp. 121-132, Gaziantep, Turkey.

Hoornweg, D., Freire, M., Lee, M.J., Bhada-Tata, P. and Yuen, B. (2011). "Cities and Climate Change: Responding to an Urgent Agenda", The World Bank, 14-32.

Huo, X. and Yu, A.T.W. (2017). "Analytical review of green building development studies", Journal of Green Building, 12(2): 130-148.

IEA (2016). 'World Energy Outlook', in IEA Report 2016, Paris, France.

Illankoon, I.M.C.S., Tam, V.W.Y., Le, K.N. and Shen, L. (2017). “Key credit criteria among international green building rating tools", Journal of Cleaner Production, 164: 209-220.

Jensen, K.G. and Birgisdottir, H. (2018). 'Guide to sustainable building certifications', in SBi and GXN Report, Denmark.

Johansson, T.B. and Goldemberg, J. (2002). 'Energy For Sustainable Development: A Policy Agenda', in United Nations Development Programme Report, USA.

Khoshbakht, M., Gou, Z., Lu, Y., Xie, X. and Zhang, J. (2018). “Are green buildings more satisfactory? A review of global evidence", Habitat International, 74: 57-65.

Kibert, C.J. (2016). Sustainable Construction: Green Building Design and Delivery, John Wiley \& Sons, Inc., Hoboken, NJ.

Kim, Y. and Sun, C. (2017). "The energy-efficient adaptation scheme for residential buildings in Kazakhstan", Energy Procedia, 118: 28-34.

Kubba, S. (2010). Green Construction Project Management and Cost Oversight, Oxford, UK: Elsevier. 
Kubba, S. (2012). Handbook of Green Building Design and Construction: LEED, BREEAM, and Green Globes, Oxford, UK: Elsevier.

Lee, W.L. (2013). "A comprehensive review of metrics of building environmental assessment schemes", Energy and Buildings, 62: 403-413.

LEED (2020). https://www.usgbc.org (Last Access: May 5, 2020). Lemma, A., Massa, I., Scott, A. and Willem te Velde, D. (2016). 'Development impact evaluation: What are the links between power, economic growth and job creation?', in CDC and Overseas Development Institute Report, UK.

Li, Y., Chen, X., Wang, X., Xu, Y. and Chen, P.H. (2017). “A review of studies on green building assessment methods by comparative analysis", Energy and Buildings, 146: 152159.

Mattoni, B., Guattari, C., Evangelisti, L., Bisegna, F., Gori, P. and Asdrubali, F. (2018). "Critical review and methodological approach to evaluate the differences among international green building rating tools", Renewable and Sustainable Energy Reviews, 82: 950-960.

Mollaoglu, S., Chergia, C., Ergen, E. and Syal, M. (2016), "Diffusion of green building guidelines as innovation in developing countries", Construction Innovation, 16(1): 11-29.

Murphy, L. (2014). "The influence of the energy performance certificate: the Dutch case", Energy Policy, 67: 664-672.

Naylor, S., Gillott, M. and Lau, T. (2018). "A review of occupantcentric building control strategies to reduce building energy use", Renewable and Sustainable Energy Reviews, 96: 1-10.

Nikolaou, T., Stavrakaki, G., Kolokotsa, D., Munteanu and C., Apostolou, A. (2015). Managing Indoor Environments and Energy in Buildings with Integrated Intelligent Systems, Switzerland: Springer.

Oberthür, S. and Ott, H.E. (1999). The Kyoto Protocol: International Climate Policy for 21 ${ }^{\text {st }}$ Century, New York, USA: Springer.

Pearce, A.R., DuBose, J.R. and Bosch, S.J. (2007). "Green building policy options for the public sector", Journal of Green Building, 2(1): 156-174.

Potbhare, V., Syal, M. and Korkmaz, S., (2009). "Adoption of green building guidelines in developing countries based on U.S. and India experiences", Journal of Green Building, 4(2): 158-174.

Reed, R., Bilos, A., Wilkinson, S. and Schulte, K.W. (2010). "International comparison of sustainable rating tools", Journal of Sustainable Real Estate, 1(1):1-22. 
Roderick, Y., McEwan, D., Wheatley, C. and Alonso, C. (2009). "Comparison of energy performance assessment between LEED, BREEAM and Green Star", 11 th International IBPSA Conference, 27-30 July, pp. 27-30, Glasgow, Scotland.

Rosen, M.A. (2009). "Energy sustainability: A pragmatic approach and illustrations", Sustainability, 1: 55-80.

Rosenow, J. and Galvin, R. (2013). "Evaluating the evaluations: evidence from energy efficiency programmes in Germany and the UK", Energy and Buildings, 62: 450-458.

Said, F.S., and Harputlugil, T. (2019). "A research on selecting the green building certification system suitable for Turkey", Grid, 2(1): 25-53.

Scheuer, C.W. and Keoleian, G.A. (2002). 'Evaluation of LEED Using Life Cycle Assessment Methods', in National Institute of Standards and Technology, Michigan, USA.

Sev, A. (2009). "How can the construction industry contribute to sustainable development? A conceptual framework", Journal of Sustainable Development, 17: 161-173.

Sev, A. (2011). "A comparative analysis of building environmental assessment tools and suggestions for regional adaptations", Civil Engineering and Environmental Systems, 28(3): 231-245.

Shan, M. and Hwang, B.G. (2018). "Green building rating systems: Global reviews of practices and research efforts", Sustainable Cities and Society, 39: 172-180.

Suzer, O.A. (2015). "A comparative review of environmental concern prioritization: LEED vs other major certification systems", Journal of Environmental Management, 154: 266-283.

Tan, H., Lei, Y. and Chen, Y. (2016). "Renewable energy development for buildings", Energy Procedia, 103: 88-93.

Waidyasekara, K.G.A.S, De Silva, M.L. and Rameezdeen, R. (2013). "Comparative study of green building rating systems: In terms of water efficiency and conservation", International Conference on Socio-Economic Sustainability in Construction: Practice, Policy and Research, 14-15 June, pp. 108-117, Colombo, Sri Lanka.

Worden, K., Hazer, M., Pyke, C. and Trowbridge, M. (2020). “Using LEED green rating systems to promote population health", Building and Environment, 172: 106550.

Wu, Z., Shen, L., Ann, T.W. and Zhang, X. (2016). "A comparative analysis of waste management requirements between five green building rating systems for new residential buildings", Journal of Cleaner Production, 112: 895-902.

Yaman, Ö., Şengül, Ö., Selçuk, H., Çalıkuş, O., Kara, İ., Erdem, Ş. and Özgür, D. (2015). "Thermal insulation in buildings and 
insulation materials", Türkiye Mühendislik Haberleri Dergisi, 487: 62-75.

Yu, S., Tan, Q., Evans, M., Kyle, P., Vu, L. and Patel, P.L. (2017). "Improving building energy efficiency in India: State-level analysis of building energy efficiency policies", Energy Policy, 110: 331-341.

Yüksel, I. and Kaygusuz, K. (2011). "Renewable energy sources for clean and sustainable energy policies in Turkey", Renewable and Sustainable Energy Reviews, 15: 41344144.

\section{Resume}

Filiz Umaroğulları is working as an Assistant Professor at Trakya University Department of Architecture since 2011. She has received her master's degree in 2001 and her $\mathrm{PhD}$ in 2011 from Trakya University Institute of Science. Her work areas are building physics, energy efficient buildings, thermal insulation and solar heat gain for buildings.

Semiha Kartal is working as Associated Professor in the Trakya University, since 2018. She has received her master's degree in 2001 and her PhD in 2009 from Trakya University Institute of Science. She studies the issues on building physics, energy efficient buildings, solar heat gain, solar energy design for buildings.

Dinçer Aydın is working as a Research Assistant in Trakya University, Department of Architecture since 2015. He got his master's degree at Architecture Program from Trakya University in 2017 and his $\mathrm{PhD}$ is still ongoing. He studies at the issues about energy simulation, indoor environmental quality and sustainable construction management. 